\title{
Para Além do Colonizado e do Subalterno: Masculinidade num Poema de Francisco José Tenreiro
}

\author{
MÁRIO CÉSAR LUGARINHO
}

Universidade de São Paulo

\begin{abstract}
This essay examines the formation of masculine identities in the colonial context of Portuguese-speaking African literatures. It does so by considering the dialectic of the colonizer/colonized in relation to hegemonic and non-hegemonic masculinities and the emergence of the "new man" in the Estado Novo and African national liberation movements.
\end{abstract}

Keywords: Colonialism, subalternity, new man, masculinities, poetry

Tendo em vista o seu caráter periférico ao cânone ocidental, na perspectiva da crítica literária dominante, as literaturas africanas de língua portuguesa deram margem ao desenvolvimento de estudos que se abrigam sob a perspectiva da subalternidade. Por esse motivo, no que tange ao gênero como elemento de problematização social e cultural, a crítica tem vindo a valorizar a produção de escritoras como vozes que se levantaram contra a histórica condição subalterna de mulheres tanto sob o colonialismo, quanto, posteriormente, no período de construção dos estados independentes.

Tornou-se incontável, especialmente no Brasil, a produção crítica a respeito das autoras dos Países Africanos de Língua Oficial Portuguesa (PALOP), seja sob a forma de monografias e teses, seja sob a forma de ensaios, artigos científicos e de divulgação, além da organização de antologias específicas diversas. Já vai longe o tempo em que eram citadas apenas as três autoras do tempo da literatura de fundação nacional (Alda Lara, Alda do Espírito Santo e Noémia de Sousa); a elas se juntaram, 
para citar algumas, Orlanda Amarílis, Vera Duarte, Dina Salústio, Conceição Lima, Ana Paula Tavares, Filomena Embaló, Lilian Momplé e Paulina Chiziane, constituindo um quadro complexo de uma produção literária em frequente ebulição.

Se por um lado, a produção dessas autoras demonstra a emergência de um sujeito cuja identidade feminina é flagrante para a constituição de um ponto de vista em contraponto a uma tradição que as subalternizou como indivíduos, por outro, a mesma ênfase da crítica deixa à mostra o privilégio concedido, sem problematizações, ao longo do século XX, à produção de autoria masculina.

Propõe-se, neste ensaio, todavia, observar, através de alguns textos que participam da fundação de algumas literaturas nacionais dos PALOPs, a formação de paradigmas que dão sentido e forma às identidades masculinas nas literaturas dos PALOPs, herdados das tradições autóctones e do colonialismo, ou formulados como projetos de ruptura efetiva com ambas as tradições. Ao mesmo tempo, procurar-se-á perceber que os indivíduos masculinos, representados em poesia e prosa, também se encontram submetidos à mesma tradição que mantém as mulheres em condição subalterna. Especial destaque é dado à obra do poeta são-tomense Francisco José Tenreiro que propõe um caminho de ruptura, ressignificando a tradição autóctone e colonial. O ensaio se assenta sobre um solo teórico constituído fundamentalmente pela contribuição de Stuart Hall e Homi Bhabha e pelos estudos das masculinidades, especialmente de Raewyn Connell e George Mosse, sem deixar de dar atenção à investigação de Goëring Therborn acerca da família no século XX, e tem por objetivo fundamental analisar algumas construções históricas e culturais de identidades masculinas no contexto da literatura produzida sob o colonialismo português.

Os estudos de gênero impuseram, quando se voltaram para o masculino, desde os estudos de Connell, na década de 1980, a questão acerca do que viria a "ser homem." Seria homem aquele que desempenhasse as atividades "naturais" destinadas à identidade masculina? A posição de atividade no ato sexual, o exercício da força física e da astúcia diante dos riscos da guerra e da caça, a defesa e o provimento de seu grupo social, a manutenção da ordem e da estabilidade social, o domínio e o conhecimento de certas tecnologias - são atividades que garantiriam o reconhecimento do "ser homem"?

Constituídos no âmbito da Antropologia e das Ciências Sociais, os estudos sobre a masculinidade se debruçaram sobre essas questões e se dedicaram a perceber, especialmente no arco de tempo da instalação da modernidade, que a identidade masculina se encontra em permanente mutação cultural, histórica, geográfica e 
social. O esgarçamento e a decadência das várias estruturas da sociedade, engendrados pelo advento da modernidade e pelo capitalismo, teriam determinado reconfigurações bastante profundas para a masculinidade. Elementos estruturantes da sociedade, como a propriedade ou o domínio sobre técnicas de sobrevivência, passaram a ser substituídos pela lógica de acumulação do capital e pelo investimento no progresso tecnológico, deslocando para instituições sociais o que estava tradicionalmente destinado aos indivíduos. ${ }^{1}$

Desse processo, resulta a desnaturalização e o estilhaçamento do paradigma da masculinidade, tradicionalmente assentada no patriarcado do Antigo Regime. A literatura europeia, instituição cultural e social privilegiada nos séculos XVIII e XIX, deu mostras significativas da mutação dessa identidade masculina, desde, pelo menos, as desventuras do jovem Werther ou do Visconde de Valmont, até a insegurança moral e social de um Armand Duval, de um Carlos da Maia ou de um Brás Cubas.

Em contraponto, heróis diversos, inseridos numa perspectiva colonial e/ou estritamente nacional, especialmente nas obras de Jonathan Swift e de Joseph Conrad, ou, mesmo, o Fradique Mendes (tanto o heterônimo coletivo da geração de 1870, quanto o personagem exclusivo da obra de Eça de Queirós), demonstravam as (novas) virtudes necessárias à constituição de uma identidade masculina para o mundo moderno. $\mathrm{O}$ aventureiro, personagem característico dessa escrita, representa o homem europeu, cujo empreendedorismo colonial o redimia da instabilidade da vida urbana e moderna.

No âmbito dos povos colonizados, localizados nas franjas dos impérios coloniais, a submissão ao colonialismo instituiu a subordinação imediata, principalmente do homem negro africano, ao agente colonial branco, e criou, no mínimo, uma hierarquia, baseada na força militar superior dos europeus. De todo modo, por força da expansão colonial europeia, as identidades masculinas locais sofreram interferências radicais e se reconstituíram relativizadas diante do colonizador. Therborn observa (66) que na África subsaariana a autonomia feminina e os largos arranjos familiares foram esvaziados pela imposição colonial da figura do chefe de família (personagem social quase desconhecido no continente), seguido pela redução do grupo à família nuclear. O homem negro africano, de maneira geral,

${ }^{1}$ Dentre os quais se destaca a promoção e o exercício da justiça, na medida em que, durante o século XIX, os estados burgueses, no ocidente, foram atenuando o direito do pater familias, até a sua total eliminação. 
passou a experimentar uma dupla condição, antagônica em seus polos: por um lado passava a exercer um protagonismo social que a sua tradição original não previa, por outro, era instalado numa posição profundamente subalterna, dada por sua origem étnica, racial e geográfica. Nas sociedades crioulas cabiam-lhe as posições subalternas, cúmplices ou marginais àqueles que efetivamente exerciam o poder na colônia (os homens brancos europeus). Além disso, a hierarquia das masculinidades se confundia com as hierarquias raciais e étnicas, mas concedia ao homem mestiço alguns poucos privilégios.

O fim do colonialismo, ao longo do século XX, e a consequente emergência das nações independentes reconfiguraram as identidades masculinas africanas, que passaram a ser uma estranha amálgama das fortes impressões deixadas pelo colonizador com as virtudes revolucionárias do "homem novo," caracterizado no discurso dos movimentos de libertação, como se percebe na produção literária mais recente (principalmente em Paulina Chiziane, mas também em João Melo, Evel Rocha, dentre vários).

Antes de prosseguir, é preciso considerar a relação existente entre o conceito de "homem novo," que poderia ser compreendido como uma forma de expressão genérica da humanidade, e a constituição das identidades masculinas na transição do século XIX para o século XX. A noção foi forjada pelo discurso religioso da catequese jesuítica, nos séculos XVI e XVII, portador de uma nova consciência de humanidade da qual resultaria a regeneração e a sublimação humana. No século XIX, o conceito de "homem novo" reaparece no pensamento nietzscheano que propõe o Übermensch (super-homem), um homem novo capaz de resistir à condição depreciada de rebanho. A proposição nietzschiana abriu margem ao futurismo de Marinetti e, principalmente, ao fascismo italiano de se apropriarem do conceito e o articularem à condição viril masculina, como se verá na apropriação nazista do conceito. Fernando Rosas observa que o Estado Novo português também forjou o seu "homem novo," atribuindo-lhe a condição de sujeito da "portugalidade" a ser desempenhada pelos homens portugueses. Segundo V. Kolbanoski, em 1923, Lênin teria formulado o conceito de "homem novo" soviético que, em 1943, o PCURSS caracterizaria como meta de todos os homens que vivessem sob o socialismo. Nessa altura, a ligação entre "homem novo" e masculinidade já parece bem consolidada, e será a partir dela que a educação e formação dos combatentes dos movimentos de libertação nacional se assentará, como se verifica nas lições de Amílcar Cabral. O PAIGC, o MPLA e a FRELIMO recorreram ao "homem novo" como modelo de 
cidadão que, sob o estado nacional independente, superaria tanto os hábitos deixados pelo colonialismo, quanto as práticas e tradições que caracterizariam o tribalismo, obstáculos para a construção do socialismo naquelas nações. Mark Sabine, ao finalizar sua análise do livro de Luís Bernardo Honwana, Nós matamos o cão tinhoso (1964), sugere que não se pode deixar de observar que a obra de Honwana recorre ao conceito marxista do "homem novo" para propor o surgimento de novas identidades para o quadro revolucionário dos movimentos de libertação. Entretanto, é possível verificar como esse conceito, presente nos discursos desses movimentos, fertilizou a produção literária dos PALOPs na medida em que se contrapunham ao conceito de "homem novo" que o próprio Estado Novo português veio a desenvolver (Lugarinho).

A identidade do homem branco, um agente do estado, um proprietário de terras, um capitalista, ou um pequeno comerciante ou artesão, foi o paradigma absoluto da masculinidade na história colonial. Naquela estrutura, tal identidade corresponderia aos militares, funcionários do estado, latifundiários, ou meros homens livres que teriam se deslocado para as colônias. Aos outros indivíduos da sociedade colonial, restava a formulação de identidades em função do paradigma, ou seja, mulheres (brancas, mestiças e negras), homens mestiços e negros e mesmo crianças (também consideradas pelo viés da raça e/ou etnia) eram contabilizados na hierarquia social colonial de maneira que, quanto mais afastados do paradigma, mais subalternamente estavam localizadas. A prática colonial portuguesa no século XX, apesar da ordenação jurídica do século anterior e dos primeiros anos da república portuguesa, manteve inúmeras características da organização social feudal, como os privilégios destinados aos indivíduos brancos do sexo masculino, mas não apenas. ${ }^{2}$

Flagra-se, assim, a Nga Muturi, de Alfredo Troni. ${ }^{3}$ É consensual que a novela de Troni é um quadro da sociedade luandense da segunda metade do século XIX e que narra a ascensão social da protagonista, ao aprofundar a sua relação com o patrão português, por via da intimidade extrema, e atingir a condição de muturi, viúva e herdeira. A cidade de Luanda, no período em que a narrativa se passa, possuía traços

\footnotetext{
${ }^{2}$ A instituição do Código Civil português de 1867, e da lei que o estendeu às colônias em 1869, definiu o conceito de família nuclear e a hierarquia entre os seus membros. Apesar da lei de 1869 considerar que o direito consuetudinário deveria ser observado e sobrepor-se ao Código nas colônias, a prática jurídica colonial foi instável (Lugarinho 23).

${ }^{3}$ Segundo as informações contidas no "Prefácio" de Mario António, Nga Muturi, do português Alfredo Troni, foi publicada entre 16 de junho a 6 de julho de 1882, no "Diário da Manhã," e de 8 de julho a 23 de agosto do mesmo ano no "Jornal da Colónia" (Troni 12).
} 
arquitetônicos e instituições características das cidades portuguesas dos trópicos, no Brasil, na África ou na Índia. Mas era também uma cidade original onde o elemento português era frequentemente dominado pela cultura crioula e africana (Vellut 361). No plano literário, a narrativa de Nga Muturi atrela-se ao realismo do seu tempo, vindo a se constituir, também, e por isso, como um documento etnográfico.

No contexto dos estudos da masculinidade, à parte tudo o que já se escreveu sobre a narrativa de Troni, o que interessa é o lugar destinado ao personagem do patrão, o muari, o homem branco, o senhor. O personagem é pouco aprofundado, há pouca notícia a respeito de seu passado e do seu sucesso financeiro: sabe-se de sua ascendência portuguesa, de sua fortuna e do poder que detém sobre as pessoas que lhe cercam; sabe-se também de sua tolerância para com as artimanhas da protagonista e da atenção a ela dispensada, e de sua acomodação pela idade avançada; sabe-se de suas propriedades e do seu testamento, de suas dores físicas e das circunstâncias de sua morte; no entanto, pouco se sabe a respeito das suas vontades, inquietações, apreensões e incertezas. Ele é construído de maneira direta e objetiva; insere-se na narrativa através de suas ações e dos resultados por elas produzidos, existe porque é o "homem," e, apesar de ser um adjuvante da narrativa, esta, sem ele, não teria sentido. Nem o seu nome é sabido. Há notícia de seu apelido por intermédio do narrador, quando nomeia a protagonista como "Nga Ndrezza," ou seja, a "Senhora Andreza," que lhe adviria do português. A não nomeação do patrão incita a concluir que sua caracterização é, na verdade, uma tipificação, uma forma de redução das características de uma personagem que passa a atender às expectativas do paradigma, mas que, no conjunto, apenas o agiganta, porque sua sombra recobre toda a extensão da narrativa. A protagonista também é nomeada segundo a função que ocupa no espaço doméstico dominado pelo português, mas que, ao contrário daquele, não se reduz a um tipo. O português é a metonímia da força política, social e econômica que rege a narrativa, o paradigma da masculinidade hegemônica, e é tornado invisível nas memórias de Nga Muturi.

A invisibilidade do português apenas reflete o lugar reservado ao homem e à identidade masculina quando tomados paradigmaticamente. Ele rege, ordena, condiciona, formaliza as sociedades e suas narrativas, mas se abstrai delas como que para sustentar a própria ordem que funda e sobre a qual se funda. Naturaliza-se. Desviá-lo do paradigma, aprofundá-lo, dar-lhe contornos de personalidade menos objetivos seria na verdade opô-lo ao paradigma - mesmo a sua avançada idade, que o tornou mais tolerante, é a submissão ao mesmo paradigma de masculinidade, 
porque, envelhecido e indisposto, passa a evitar novos enfrentamentos, admitindo as circunstâncias e contingências da vida. O muari, naquele contexto histórico, poderia vir a representar, diante de um público leitor português, a inscrição dos paradigmáticos heróis nacionais, celebrados na mesma altura na realidade cotidiana. Afinal, o muari é a rememoração do poder que a metrópole impunha aos "indígenas," ao mesmo tempo em que são afirmadas, aos olhares daquele tempo, características de cordialidade e entendimento, fundamentos da masculinidade do século XIX, diante dos mesmos indígenas.

Incapacitados de se reconhecerem como conquistadores aos moldes dos heróis nacionais, resta-lhes, como restaria a Gonçalo Mendes Ramires de Eça de Queirós, se reconhecerem como comerciantes, senhores de escravos e amantes de mulheres "bárbaras" que lhes devem a existência e a sobrevivência. ${ }^{4}$

De maneira diversa, anos mais tarde, Francisco José Tenreiro apresentará a sua versão do muari. Ilha de nome santo, publicado em 1942, pode ser lida sob esse viés, ao se voltar a tipos sociais do universo colonial, dos quais se destaca a personagem do "Seu Silva Costa," que recebe a atenção em dois poemas (nas partes "Romanceiro" e "Ciclo do Álcool") (13-14, 23). Seu Silva Costa, ao emigrar para as ilhas, transita de uma condição subalterna e se converte em homem de negócios bem-sucedido no espaço colonial. Importa não apenas observar sua adequação ao paradigma, mas ser reconhecido naquele mesmo espaço colonial, onde são destacadas as suas lutas contra as adversidades locais ao mesmo tempo em que são apontados os ardis de que lançou mão para conquistar sua posição social. Na perspectiva de Tenreiro, o "Seu Silva Costa" é um paradigma do português colonizador, mas nele não se encontram as mesmas virtudes fixadas por Troni. Nesta outra face do muari, observada pelo poeta, percebem-se as vicissitudes do colonialismo, concentradas num estereótipo, problematizado, que atualiza o português de Troni.

Ao lado do "Seu Silva Costa," Tenreiro dá atenção na "Canção do mestiço" (1920) ao personagem social subalterno que se submete aos estereótipos da sensualidade masculina do homem africano. Mesmo que se encontre numa intersecção étnica e racial, porque é branco ou negro conforme a situação, seu lugar no leito da mulher

\footnotetext{
${ }^{4}$ Publicada em 1882, Nga Muturi ainda estava longe da emergência no imaginário colonial de Mouzinho de Albuquerque, comandante militar da campanha de "pacificação" de Moçambique (1894-1895), alçado à condição de herói nacional português logo após a derrota do Gungunhana.
} 
branca ou da mulher negra é garantido. Ou seja, na esfera da intimidade, o exercício do gozo é garantido ao homem na medida em que afirma sua virilidade, traço incontestável da sua identidade masculina num espaço e num tempo de identidades fixas. O mestiço comparece como indivíduo contrário aos anseios de paradigmas que se contraponham ao paradigma do colonizador, (re)criado em "Seu Silva Costa"na verdade, num momento em que se estabelecem identidades fixas, juridicamente, até, em culturas dotadas de uma "origem," o mestiço representa uma zona de sombra e desconfiança, incapaz de apresentar um traço de solidariedade legítimo aos povos subalternizados. Igualmente apresentado como ardiloso, mas de maneira irônica, não pode representar um paradigma porque, apesar de desempenhar atitudes próprias daqueles que exercem a masculinidade hegemônica, os mestiços também estão subalternizados. Eles são identificados com os requisitos parciais de sua subjetividade, que se encontra ao sabor tanto de seus interesses quanto dos que se situam no campo hegemônico (o paradigma do homem moderno deveria apresentar firmeza de caráter e não ceder aos seus valores e desejos individuais). Certamente, por isso, Tenreiro, em "Epopeia" (29-33), constrói um novo paradigma para o homem negro, que tanto representasse a coletividade africana quanto a masculinidade autêntica que se opusesse ao paradigma do colonialismo.

A fim de investir na autonomia política, e poética, do homem negro, contrapondo-o ao conquistador/colonizador, Tenreiro (re)constitui uma epopeia negro-africana. Nesse poema não convoca um herói nacional, um paradigma que fosse a reconstituição ou leitura de guerreiros, cavaleiros, conquistadores ou navegadores (sempre identificados com a constituição colonial), mas convoca um homem negro oriundo de outro universo, capaz de inscrever a África, e o homem negro e africano, numa outra ordem, diversa ao colonialismo e ao imperialismo moderno.

A eleição de Jesse Owens (“Quando nas Olimpíadas / corres veloz / é a África que está chegando!" (32)) como modelo de masculinidade, ao lado de Josephine Baker, a mesma "negrinha" de "Negros de todo mundo" (35-40), para formar o casal primordial de uma "África que está chegando," dá contas da necessidade de reconhecer, em contraposição aos modelos disponíveis até então, um novo paradigma de masculinidade para o homem africano em oposição aos paradigmas do colonizador português ou dos paradigmas de uma tradição africana. Owens é um atleta olímpico, não é nem a antítese do colonizador/conquistador branco que abre "clareiras / a tiros de carabina," (29) nem é o guerreiro africano em sua forma 
tradicional. Owens é aquele cuja imagem se constitui como síntese entre "os gritos agudos da azagaia" e uma modernidade que Rui de Noronha em Moçambique requisitara em seu poema "Surge et ambula" (42).

A presença de Jesse Owens na poesia de Tenreiro merece atenção. $O$ atleta norte-americano, nas circunstâncias em que sua imagem emergiu mundialmente, o tornou singular e por isso paradigmático. $\mathrm{O}$ esporte passou a fazer parte efetiva da educação formal masculina durante o século XIX no ocidente a fim de que fossem aplacadas as atitudes violentas de meninos em colégios burgueses e fossem acirradas a competitividade e a solidariedade entre grupos. A prática desportiva foi estimulada porque além de formar homens fortes e viris fisicamente, identificava os atletas como a excelência de uma raça e, por conseguinte, de uma nacionalidade, não apenas em termos de força e habilidade, mas de coragem, inteligência e honra (Mosse 61).

Para a poesia africana produzida em língua portuguesa, alguns meios de comunicação e objetos da cultura de massa provocaram a busca por novas formas de expressão, propiciando o aparecimento de discursos identitários que se enraizavam no solo africano, como o cinema na poesia de José Craveirinha, ou o rádio na poesia de Noêmia de Sousa. Ao seu lado, a fixação de uma memória africana, no texto literário, isolaria o sujeito da condição histórica do colonialismo, conformando uma estética para o corpo negro, obliterado em toda estética da literatura ocidental—o corpo negro de Owens tornou-se, em Tenreiro, o lugar onde se verifica o continuum entre o passado ancestral e o futuro desprovido da condição colonial. Se uma memória ancestral subjetivava o homem e a mulher negros no espaço dominado pelo homem branco, o corpo negro atlético, vigoroso e belo inscreveria esse homem e essa mulher num projeto de autonomia absoluta. Recorde-se que a beleza desses corpos não se encontra isolada, ela aparece em função de outras características, esportivas ou artísticas, que os distanciam decididamente de quaisquer discursos eugenistas.

Mosse (44) alerta para a necessidade de composição harmoniosa entre a beleza do corpo e o caráter do homem que o encarna, quando da emergência da identidade masculina moderna, o que seria exatamente o caso do corpo de Owens, ao qual se acresce a sua honra demonstrada nas vitórias e sua posição solitária sobre o pódio diante da massa de espectadores alemães. Jesse Owens e Josephine Baker foram as primeiras imagens de corpos negros, em perfeitas condições físicas e que atendiam aos requisitos modernos da estética do corpo físico, de beleza, força e vigor, disseminados pela cultura midiática internacional. 
Owens não era africano. Mas sua origem era um atestado suficiente para que Tenreiro o inserisse em sua poética e, com isso, o instalasse no lugar privilegiado que o poema lhe confere. Assim, Owens, ao lado de Baker, pode ser inscrito pela poesia de Tenreiro na memória africana. Evoque-se apenas Bakhtin (397-428) e Benjamin (197-221) para somente avivar a já tão decantada relação entre memória e discurso épico que, aqui, não cabe discorrer a respeito.

A elevação de Owens à condição paradigmática define o movimento em que se verifica, no conjunto das literaturas africanas de língua portuguesa, para a emergência de novos paradigmas de masculinidade, efetivamente capaz de se contrapor ao paradigma do colonizador e, mais ainda, do colonizado. Como já se disse acima, Owens não apenas é um homem moderno porque ganhou destaque por suas vitórias olímpicas - a dimensão de suas vitórias em 1936 nos jogos olímpicos de Berlim, conferiu-lhe estatuto de herói supranacional - mas porque, com ele, se deu a vitória da alteridade no espaço reservado à celebração da uniformidade e da homogeneização cultural e étnica. Para Tenreiro, a partir de "Epopeia," Owens tornava-se o modelo capacitado a substituir o paradigma definido pelo colonialismo. Sua condição paradigmática, entretanto, não se percebe na celebração contínua do personagem histórico que foi Jesse Owens mas nas virtudes que encarnou. O poema de José Craveirinha, "Grito negro," evidencia procedimento semelhante visto que, ao ressignificar a palavra "carvão," o poeta moçambicano desloca-a da condição de subalternidade, reconhecendo na palavra a sua potencialidade de significação ao repetir por várias vezes o verso "Eu sou carvão!” (13-14) carvão que gera combustão e queima o patrão. Ao afirmar o que é, carvão, o homem negro rompe a condição subalterna e altera o padrão de representação a que foi submetido. A ressignificação aproxima-se do mesmo procedimento realizado por Tenreiro com Owens.

Para compreender como as qualidades apontadas em Owens se constituíram paradigmáticas na poesia de Tenreiro é preciso ainda recorrer ao conceito de agenciamento, tal como Gilles Deleuze e Félix Guattari o desenvolveram e como Homi K. Bhabha o estendeu aos contextos colonial e pós-colonial.

Deleuze e Guattari (112) estabeleceram uma relação direta entre o discurso, o sujeito e os indivíduos que, através dessas instancias, se relacionam entre si e com as instituições que criam e nas quais reconhecem o poder de geri-los. O agenciamento é não apenas a forma como os indivíduos acessam o real, mas a sua própria forma de estar no mundo - submetidos às ordens discursivas, ao mesmo tempo em que as escamoteiam e delas escapam, constituindo a sua própria e específica forma de estar 
no mundo, lato sensu, a sua individualidade (Zourabichvili 9). Sendo então reconhecido como o processo de singularização do indivíduo, ao mesmo tempo em que é a sua maneira de se relacionar com o mundo, o agenciamento não é, entretanto, uma forma de relação entre o individual e o coletivo porque ele é coletivo em suas formas. $\mathrm{O}$ agenciamento se dá sob dois modos do coletivo, na medida em que se constitui nos sentidos do coletivo. Se for verdade que o agenciamento é individualizante, ele não se enuncia do ponto de vista de um sujeito preexistente que lhe poderia ser atribuído.

Michel Foucault já demonstrara que formações discursivas eram dispositivos de produção de corpos submetidos e mentes assujeitadas, que fabricavam subjetividades e corporeidades em uma série de instituições como as famílias, escolas, quartéis, fábricas, hospitais, prisões, universidades etc. Para Deleuze e Guattari, no entanto, o agenciamento faz os modos econômicos e os regimes políticos dependerem de regimes de sensibilidade e regimes de linguagem, conforme aponta Luís Fuganti: "O conceito de agenciamento torna-se então um operador de primeira ordem, uma vez que remete ao modo concreto de produção de realidade, em qualquer dimensão, material ou imaterial, e não à verdade que representaria o real."

Bhabha, por sua vez, observou que Frantz Fanon, ao enunciar a pergunta "o que quer um homem negro?” (71), privilegiando as instâncias psíquicas, ampliava a dimensão política do colonialismo para além de um humanismo liberal, mas reconhecia que não há uma narrativa mestra que forneça um repertório de fatos sociais e históricos contra os quais emergiriam os problemas da psique individual ou coletiva do homem colonizado. Para Bhabha, Fanon percebera que o "homem negro," o sujeito colonial, é resultado de um alinhamento da sociedade, da história e da psique ou da associação heterogênea dos textos da história, da literatura, da ciência e do mito. Segundo Bhabha, "o sujeito colonial é sempre 'sobredeterminado de fora', escreve Fanon. É através da imagem e da fantasia-aquelas ordens que figuram transgressivamente nas bordas da história e do inconsciente- que Fanon evoca a condição colonial de forma mais profunda" (71).

A reflexão de Bhabha a respeito de Fanon impõe que se observe o processo empreendido por Tenreiro ao eleger Owens como paradigma de um agenciamento em que é subvertida não apenas a ordem colonial, mas sobretudo a ordem de gênero típica do colonialismo na qual a masculinidade seria exercida por um sujeito 
efetivamente identificado com paradigmas oriundos do ocidente. ${ }^{5}$ Através de Owens, a poesia de Tenreiro pode superar a dialética do senhor e do escravo e, sobretudo, a dialética do colonizador/colonizado já que Owens se sobrepôs a qualquer dispositivo anterior sobredeterminado pela condição colonial, inaugurando efetivamente uma nova forma de ser homem e homem negro. Decerto, o procedimento não é exclusivo de Tenreiro, já que vários outros autores comprometidos com os movimentos de libertação (como Honwana, Luandino Vieira, Pepetela, dentre vários), com maior ou menor sucesso, recorreram a estratégia semelhante de subversão do colonialismo, mas, também, à ordem de gênero.

A ordem de gênero, mais flagrantemente no espaço colonial, está articulada aos marcadores étnicos, raciais e de classe. O colonialismo abrira espaço amplo para a instauração de peculiaridades das identidades hegemônicas e apenas o agenciamento de novas subjetividades poderia efetivamente relativizar e subverter o exercício da masculinidade hegemônica. Nesse sentido, "A canção do mestiço" ganha outro estatuto porque demonstra exatamente a brecha possível na estrutura articulada por aqueles marcadores, mas, insiste-se, subsiste na e pela ordem colonial.

Ao mesmo tempo, a estratégia discursiva dos movimentos de libertação, assentada sobre o conceito de "homem novo," estaria na base desse agenciamento ao questionar, superar e negar a ordem colonial e, por conseguinte, o exercício da masculinidade hegemônica por parte do colonizador. ${ }^{6}$ Owens, em Tenreiro, supera a dialética do colonizador/colonizador não apenas porque rasura o paradigma da subalternidade, mas porque propõe um novo paradigma que se instalou no horizonte das Literaturas Africanas de Língua Portuguesa.

Entretanto, apesar da obra de Tenreiro, a representação das masculinidades nas literaturas africanas não se isolou dos modelos oferecidos pela cultura ocidental. $\mathrm{Na}$ vida social, como Therborn afirma (64-65), o colonialismo impôs o modelo de

\footnotetext{
5 "Ordem de gênero" é conceito Connell em que se reconhece um padrão que sistematiza a criação de homens e mulheres e as relações por eles e entre eles travadas.

${ }^{6}$ Tanto o PAIGC, quanto o MPLA e a FRELIMO recorreram a esse conceito emanado do PCURSS como estratégia de reeducação e consequente regeneração dos homens africanos, que deveriam ser resgatados do confronto do colonialismo com as tradições autóctones. A melhor definição do conceito de "homem novo" foi dada por Amílcar Cabral (70) que destacara que o "homem novo" deve ser consciente dos seus direitos e deveres nacionais, continentais e internacionais-desvinculado de uma submissão estreita à nacionalidade, convertido em cidadão, pleno de direitos e deveres, e que reconhece a sua temporalidade e sua espacialidade de maneira alargada. Ou seja, a submissão desse homem ao estado não é condição para o seu reconhecimento, mas, para que se atinja esse estatuto é preciso que se faça uma profunda reforma cultural.
} 
família nuclear em leis e práticas e definiu papéis sociais, masculinos e femininos, que perduram para além das independências. $\mathrm{O}$ modelo proposto por Tenreiro em sua obra poética não foi suficiente para impulsionar a superação do paradigma colonial e gerar novas e outras representações da masculinidade; contudo, abriu lacunas a partir das quais se iniciou o questionamento dos papéis sociais impostos, juntamente às contradições que a inserção do capital nas colônias veio a determinar.

Entre o paradigma de Tenreiro e a evidenciação de crises da identidade masculina, como, por exemplo na obra do caboverdiano Fernando Monteiro, $\mathrm{Na}$ roda do sexo, o projeto de "homem novo," apesar de mais aproximado da representação levada a cabo por Tenreiro do atleta Jesse Owens, não se abstraiu da lógica colonial. ${ }^{7}$ Neste sentido, o processo de instauração do "homem novo" foi o caminho mais recorrente em obras literárias nas quais a identidade masculina dava acesso à utopia política. Para tanto, foi necessária a problematização da identidade masculina tal como fora constituída nos tempos do colonialismo. Espremido entre o presente da vida colonial e a utopia futura, o homem africano, daqueles tempos, já seria um indivíduo dotado de uma identidade de gênero em crise.

Apesar disso, o "homem novo" se constituiu como personagem e horizonte das obras que marcaram os anos das lutas de independência. Está presente em Arnaldo Santos, Luandino Vieira, Pepetela, Manuel Lopes e Honwana, estabelecendo muitas vezes identidades rigidamente constituídas sobre um perfil épico mais significativo, como João da Cruz, d'Os flagelados do vento leste de Manuel Lopes (1959). Nos primeiros momentos de constituição das literaturas nacionais, principalmente para que afirmasse a distância que separava a identidade dos povos africanos das identidades europeias fragmentadas, foi preciso que aquelas literaturas fossem construídas a partir de formações discursivas que instalassem identidades rigidamente calcadas no perfil épico de heróis que se nacionalizavam. O desenvolvimento literário mais recente vem apontando, no entanto, sentidos diversos para a identidade masculina que não a do herói tradicional. O aburguesamento social, promovido pelo capitalismo tardio, já globalizado, que instituiu sociedades de consumo em toda parte, impõe uma revisão clara dos vetores que orientam a

\footnotetext{
${ }^{7}$ Ao longo de doze contos, publicados em 2009, o cabo-verdiano Fernando Monteiro se dedicou a explorar a experiência da sexualidade em situações diversas. Do conjunto de contos destaca-se, pela recorrência, o confronto dos personagens masculinos diante de supostas contradições que problematizam a vigência de uma identidade masculina estável, homogênea e, consequentemente, hegemônica.
} 
formulação das identidades masculinas nas Literaturas Africanas de Língua Portuguesa na medida em que valores masculinos tradicionais vão sendo colocados em causa explícita, principalmente pela superação cada vez mais flagrante da tensão entre colonizador e colonizado na expressão literária. O questionamento acerca do homem e da identidade masculina, sugerido por uma produção literária mais recente, coloca em causa tanto a tradição, quanto a configuração dos valores da utopia social e política que animou tantos anos de crítica e literatura.

\section{Obras Citadas}

António, Mário. "Prefácio." Nga Muturi: cenas de Luanda, de Alfredo Troni. Edições 70, 1973, pp. 7-27.

Bakhtin, Mikhail. Questões de literatura e estética: a teoria do romance, tradução de Aurora Fornoni Bernardini et al., Hucitec e U Estadual Paulista, 1988.

Benjamin, Walter. Magia e técnica, arte e política: ensaios sobre literatura e história da cultura, tradução de Sérgio Paulo Rouanet, Brasiliense, 1994.

Bhabha, Homi. O local da cultura, tradução de Myriam Ávila, Eliana Lourenço de Lima Reis e Gláucia Renate Gonçalves, U Federal de Minas Gerais, 1998.

Cabral, Amílcar. Livro, www.amilcarcabral.org/livro.pdf.

Connell, Raewyn W. "A Very Straight Gay: Masculinity, Homosexual Experience and the Dynamics of Gender." American Sociological Review, vol. 57, 1992, pp. 735-51.

Craveirinha, José. Xigubo. $2^{\circ}$ ed. Instituto Nacional do Livro e do Disco, 1980.

Deleuze, Gilles and Felix Guatari. Kafka. Por uma literatura menor, tradução de Júlio Castañon Guimarães, Imago, 1977.

Foucault, Michel. A ordem do discurso, tradução de Laura Fraga de Almeida Sampaio, Loyola, 1996.

Fuganti, Luiz. "Agenciamento." Escola Nômade, 24 Fev. 2016, escolanomade.org/ 2016/02/24/agenciamento/.

Kolbanoski, Viktor Nikolaevich. "A moral comunista." Problemas, vol. 17, 1949. Marxists Internet Archive, www.marxists.org/portugues/tematica/ rev_prob/17/moral.htm.

Lopes, Manuel. Os flagelados do vento leste. Ulisséia, 1959. 
Lugarinho, Mário César. "Masculinidade e colonialismo: em direção ao "homem novo" (subsídios para os estudos de gênero e para os estudos pós-coloniais no contexto de língua portuguesa).” Abril, vol. 5, no. 10, 2013, pp. 15-38.

Monteiro, Fernando. Na roda do sexo. Soca, 2009.

Mosse, George. La imagen del hombre: la creación de la moderna masculinidad. traducción de Rafael Heredero, Talassa, 2000.

Noronha, Elsa de, editor. África, surge et ambula: Rui de Noronha-poeta moçambicano. Espaço Rui de Noronha-Associação, 2006.

Rosas, Fernando. "O salazarismo e o homem novo: ensaio sobre o Estado Novo e a questão do totalitarismo." Análise Social, vol. 35, no. 157, 2001, pp. 1031-54.

Sabine, Mark. “A emasculação de África e a crise do patriarca negro." Via Atlântica, vol. 17, 2010, pp. 187-200.

Tenreiro, Francisco José. Ilha de nome santo: novo cancioneiro 9. Atlântida, 1942.

Therborn, Göran. Sexo e poder: a família no mundo 1900-2000, tradução de Elisabete Doria Bilac, Contexto, 2006.

Troni, Alfredo. Nga Muturi: cenas de Luanda. Edições 70, 1973.

Vellut, Jean-Luc. “A bacia do Congo e Angola.” História geral da África: África, do século XIX à década de 1880, edição de J. F. Ade Ajayi, Organização das Nações Unidas para a Educação, a Ciência e a Cultura/Ministério da Educação, Brasil, 2010, pp. 343-77.

Zourabichvili, François. O vocabulário de Deleuze, tradução de André Telles, Sinergia-Relume Dumará, 2004. 